\title{
Relationship between parents' defense mechanisms and personal supportive factors with coming-to-terms behaviors in university students
}

\author{
Fahime Nedaie Haddad \\ Department of Educational Psychology, College of human science \\ Saveh Branch, Islamic Azad University, Saveh, Iran. \\ Email: nefahimeh@yahoo.com \\ Asghar Ja'fari \\ Faculty Member in Department of Educational Psychology \\ Email: drasgharjafari@yahoo.com \\ Neda Nouhi \\ Department of Educational Psychology, College of psychology and social science \\ Central Tehran Branch, Islamic Azad University, Tehran, Iran \\ Email: nedanoohi@yahoo.com
}

Received: February 23, 2015 Accepted: February 29, 2016 Published: April 17, 2016

doi:10.5296/ijafr.v6i1.9404 URL: http://dx.doi.org/10.5296/ijafr.v6i1.9404

\begin{abstract}
The present study was aimed to determine the relationship between parents' defense mechanisms and personal supportive factors with coming-to-terms in students. The study used a correlational method; and the statistical population consisted of all students of BA and upper levels, who referred to Tehran's national library during the first half of 2013, from whom 90 individuals were selected as the sample of the study, using random sampling method. They completed Andrews' et al (1993) defense styles questionnaire, Zimet's et al Multi-Dimensional Scale of Perceived Social Support (MSPSS), and Britani Hermandz's Coming-to-Terms behaviors (2008). Frequency, mean, deviation, standard, Pearson correlation coefficient, and multivariate regression analysis were used in order to analyze data. Results showed that there is a relationship between parents' developed defense mechanisms, underdeveloped defense mechanisms, and neurotic defense mechanisms, and personal supportive factors with students' coming-to-terms behaviors. From predictor variables, personal supportive play a have a greater share in the expression of students' coming-to-terms behaviors. Finally, it can be concluded that considering the role of defense mechanisms in mental health, and considering the fact that
\end{abstract}


different defense mechanisms affect individuals' stressful emotions in various ways, clinical experts and consultants can help patients to develop defense mechanisms and review personal and social supportive factors, following which we can expect them to better face this negative emotion and come to terms with it.

Keywords: Parents' defense mechanisms, personal supportive factors, students' coming-to-terms behaviors

\section{Introduction}

Today, the complexity of life conditions is to such a degree that it produces tension and stress in most humans. Hence, humans must try hard in order to adapt to the environment or fight problems (Joshi, 2007). Anxiety is a risk sign showing that things are no going well. Therefore, anxiety informs individuals of threats and of the fact that if nothing is done, they might fall apart. In order to neutralize or reduce anxiety, they must endeavor to reduce conflicts between Id demands and super-ego strictness (behaviors). Hence, defense mechanisms are used as tools for reducing anxiety and tension stemming from Id demands and surrounding super-ego orders. The concept of defense mechanisms is one of the most important mental analysis contributions in the study of personality. Freud was the first person to put forward the presence of a number of defense mechanisms. In 1936, Freud defined defense mechanisms as intellectual mechanisms which protect individuals against the anxiety that results from external stressful events and internal destructive states. The protective role of defense mechanisms is realized through moderation, deviation, or deletion of stressful thoughts, emotions, and perceptions (Offer, Lavie, Gothelf and Apter). Freud introduced a number of defense mechanisms and stated that we rarely use only one of these mechanisms; and by using several mechanisms at the same time, we protect ourselves against anxiety. There is a little overlap between these mechanisms. Even though these mechanisms are different in terms of details, they have two common qualities:

Denial or falsification of reality and unconscious activity (Cramer, 2002). These mechanisms are learned from infancy until they become habits. In line with this, one of the factors helping individuals to adapt themselves in stressful situations is that they seek social support. Support factors are referred to as qualities that reinforce adaptability (Martinez-tertia, Begat, Vinay and Lunusky, 2009). Supportive factors have been selected based on three factors by Werner (1989), and Luthar and Ziegler (1994); these factors are: 1) personal qualities (such as independence, intellectual ability, and responsiveness), 2) family safe and warm relationship, 3) and accessibility of ultra-family supports (such as friends and teachers) (Greenberg, 2006). Sarason (2004) believes that when an individual comes to believe that they need people to get help from, they become more capable of coming to terms with problems like marital conflicts, leading them to make wise decisions for solving problems. Considering the fact that the presence of friends, acquaintances, and family members can psychologically affect individuals' self-esteem, confidence, and defense styles, those who experience positive social and personal support become more capable of resisting and coming to terms with challenges (Amato and Rogers, 2003). Coming-to-terms skill is a set of activities and cognitive-behavioral processes which help to resist, mange, or reduce stress. According to Lazarus and Folkman (1984) 
coming-to-terms skill is an effort to manage and adapt to situations not to control and dominate them. They refer to two types of known general resistance: Problem-focused resistance which helps to solve problems or take actions change stress source; and emotion-focused resistance which helps to reduce or manage conflicts, using methods which are based on emotional patterns.

Galager et al (2003) refer to coming-to-terms skill as personal efforts in emotion, cognition, and behavior fields which are used when facing mental pressures in order to dominate, stand, or minimize tension. Therefore, it can be said that: 1) resistance or coming-to-terms is a process; 2) cognitive evaluation plays an important role in the style of coming-to-terms; 3) coming to terms depends on efforts (cognitive, behavioral, and emotional); 4) resistance for the purpose of maintaining mental health. Individuals' ability when coming to terms with problems and their forms depend upon external and internal mental factors. According to WHO (2000), resistance skills include ten skills: problem-solving, creative thinking, critical thinking, self-awareness, sympathy for others, fighting emotions (failure, anxiety, depression, and so on), and resistance to stress. What is important is that all of these skills can be acquired; these skills assist individuals in controlling problems such as depression, anxiety, loneliness, banishment, timidity, fury, conflict in inter-personal relationships, failure, and loss. Since university students are studying at university, because the society has more expectations for them, and because they have to adapt themselves to a new lifestyle and stresses stemming from academic problems, they are likely to experience psychological problems such as: depression, physical complaints, drop in social performance, and intense anxieties, which can lead to poor academic performance, personal and social tensions, communicational problems on the campus, and blockage of talents. Considering education psychologists and cognition psychologists' interest, and the effect stress has on students' behavior and occupational-educational programs, numerous studies have been done inside and outside Iran, which are: In the community of Iranian students, Dadsetan (2008) shows that in all passive strategies helping to avoid stressful factors, men's scores were higher than women's. Qaedi and Yaqubi (2008) found that having favorable social support leads individuals to physical and mental health; hence family social support is a predictor for girls. On the contrary, social support for boys is provided more by friends. Norouzi Dayni (2002) showed that those who possess more personal and environmental resources such as high income, multiple friends, good job, supportive family relationships, optimism, and high reverence use active resistance. In a study, Cramer (1998, 1997, according to Cramer and College, 2002) found that denial at the age of five is normative and appropriate. Lungir (1976) stated that in low levels of development, individuals use less mature defense mechanisms. Defense mechanisms such as projection and breaking things are more seen in men; Defense mechanisms such as introjection like standing against oneself are more seen in women (Cramer and College, 2002). Moris and Mercerbach (1994) found that defense style of patients with clinical anxiety has a relationship with trait anxiety scores of normal respondents. They also reported defense scores and the scores of trait anxiety and physical signs to be different. But they did not manage to find significant defense styles and defense mechanisms. Gentery et al (2007), concluded that there are significant differences between the two genders in terms of tension. The results obtained from this study, in line with the results obtained from previous studies (such as Matud, 2004; Mc Doonough and Walterts, 
2001; according to Dadsetan, 2008), showed that the levels of perceived tension in men are higher than in women. Studies done by Bart et al, (2001), Kashani, and Orvaschel (1990) showed that anxious adults perceive unclear things stories as threats and enjoy wishful thinking. They daydream, deny the present, and avoid it.

According to the role of parents' defense mechanisms and personal supportive factors in coming-to-terms behaviors in university students, the present study, by determining the relationship between parents' defense mechanisms and personal supportive factors with coming-to-terms behaviors in students, was aimed to find an answer to the research question:

- Is there a relationship between parents' defense mechanisms and personal supportive factors with coming-to-terms behaviors in university students?

\section{Methodology}

The present study was a fundamental and non-experimental research which was done using a correlation method.

\subsection{Statistical population, sample, and research sampling method}

In this study, the statistical population consisted of all students of BA and upper levels, who referred to Tehran's national library and were members of this library. For sampling, using the list of members, 90 individuals were randomly selected as research sample; and they completed the study's questionnaires.

\subsection{Research Tool}

Defense styles questionnaire:

This questionnaire was provided based on a hierarchical pattern of defense by Andrews et al (1993), including 40 questions in a 9-point Likert scale (from totally agree to totally disagree), evaluating 20 defense mechanisms in three levels: developed, underdeveloped, and neurotic.

Multi-dimensional scale of perceived social support (MSPSS):

This questionnaire was provided by Zimet et al in 1988 in order to evaluate perceived social support from families, friends, and other significant friends in life. This tool includes 12 items each of which is in a 5-point Likert scale (from totally disagree to totally agree). All items are scored directly. Authors of this tool and many other researchers (such as Edwards 2004, Chang and Chan, 2007) have supported the reliability and validity of this tool.

Coming-to-terms behaviors questionnaire:

This questionnaire was provided by Britani Hernandez in 2008 in order to measure the level of children's coming-to-terms behaviors. This version includes 83 limit evaluation terms from resistive behaviors. Coming-to-terms strategies have been examined based on a 4-point scale (from "never" to "almost always").

\subsection{Implementation Style}

In this study, first, after receiving a permit from university, we referred to Tehran's national 
library; and after the explanation of the purpose of the study and ethical rules, parents' defense mechanisms questionnaire, personal supportive factors questionnaire, and coming-to-terms behaviors questionnaire were given to respondents; and they were asked to honestly answer questions. Then, questionnaires were marked, and finally, data were analyzed using statistical tests.

\section{Analysis}

After being collected, research data were extracted and coded using SPSS software, and the data related to research variables were analyzed using descriptive statistics indexes such as mean, standard deviation, frequency distribution tables, as well as inferential statistics method through multivariate regression methods and Pearson Correlation Coefficient method.

\section{Finding}

In the descriptive statistics section, mean descriptive statistics and standard deviation of research variables corresponding to respondents have been presented in the table below.

Table 1: Descriptive indexes of research variables

\begin{tabular}{|c|c|c|c|c|c|}
\hline variable & number & mean & $\begin{array}{c}\text { Standard } \\
\text { deviation }\end{array}$ & Lowest score & $\begin{array}{c}\text { Highest } \\
\text { score }\end{array}$ \\
\hline $\begin{array}{c}\text { Developed } \\
\text { defense } \\
\text { mechanisms }\end{array}$ & 60 & 8.66 & 1.55 & 5.86 & 14 \\
\hline $\begin{array}{c}\text { Underdeveloped } \\
\text { defense } \\
\text { mechanisms }\end{array}$ & 60 & 19.43 & 3.12 & 14.79 & 27.26 \\
$\begin{array}{c}\text { Neurotic } \\
\text { defense }\end{array}$ & 60 & 8.25 & 1.95 & 3 & 14 \\
\hline $\begin{array}{c}\text { mechanisms } \\
\text { Personal }\end{array}$ & 60 & 6.30 & 1.78 & 3.5 & 181 \\
\hline $\begin{array}{c}\text { supporters } \\
\text { Coming-to-terms }\end{array}$ & 60 & 119.31 & 13.43 & 95 & \\
\hline behavior & & & & & \\
\hline
\end{tabular}

As it can be seen in table 1, descriptive statistics such as sample size, mean, standard deviation related to defense mechanisms, personal supportive factors, and coming-to-terms behavior in students. Considering the mean of variables, and calculated standard deviations corresponding to each variable, we can observe the dispersion level of respondents' scores.

Hypothesis: There is a relationship between parents' defense mechanisms and personal supportive factors with students' coming-to-terms behaviors. After determining the normality of data distribution, in order to analyze relationships between research variables, multivariate regression statistical methods were used. 
To test this hypothesis, multivariate regression analysis was used through ENTER method; the summary of the results of multifold regression analysis model has been reported in table 2 .

Table 2: Summary of multifold regression analysis model

\begin{tabular}{|c|c|c|c|c|}
\hline model & $\mathbf{R}$ & $\boldsymbol{R}^{\mathbf{2}}$ & moderated & $\mathbf{S E}$ \\
\hline $\mathbf{1}$ & 0.773 & 0.598 & 0.569 & 8.82 \\
\hline
\end{tabular}

Predictor variables: developed defense mechanisms, underdeveloped defense mechanisms, and neurotic defense mechanisms, and personal supportive factors

As it can be seen in table 2, the relationship between parents' defense mechanisms and personal supportive factors with coming-to-terms behavior was calculated. Its value was $0.773,59.8$ of which expressed changes related to coming-to-terms behavior.

Table 3: Summary of results obtained from the variance analysis for regression model significance

\begin{tabular}{|c|c|c|c|c|c|}
\hline $\begin{array}{c}\text { Change } \\
\text { Sources }\end{array}$ & Sum of square & $\begin{array}{c}\text { Degree of } \\
\text { freedom }\end{array}$ & Mean square & F & $\begin{array}{c}\text { Significance } \\
\text { level }\end{array}$ \\
\hline Regression & 6372.1 & 4 & 1593.02 & 20.47 & 0.001 \\
\hline residual & 4278.88 & 55 & 77.79 & & \\
\hline Total & 10650.98 & 59 & & \\
\hline
\end{tabular}

Predictor variables: parents' developed defense mechanisms, underdeveloped defense mechanisms, neurotic defense mechanisms, and personal supportive factors

As the contents of the table show, variable such as developed defense mechanisms, underdeveloped defense mechanisms, neurotic defense mechanisms, and personal supportive factors significantly $(\mathrm{F}=20.47, \mathrm{p}<0.05)$ predict coming-to-terms behavior in regression model.

Table 4: Summary of regression coefficients for developed defense mechanisms, underdeveloped defense mechanisms, and neurotic defense mechanisms, and personal supportive factors

\begin{tabular}{|c|c|c|c|c|c|}
\hline Final model & $\begin{array}{c}\text { Regression } \\
\text { coefficient (B) }\end{array}$ & SE & $\begin{array}{c}\text { Standard } \\
\text { coefficient } \\
\text { (Beta) }\end{array}$ & $\mathbf{t}$ & Significance \\
\hline Fixed value & 125.81 & 13.05 & & 9.63 & 0.001 \\
\hline developed & 1.32 & 0.800 & 0.154 & 1.66 & 0.102 \\
\hline underdeveloped & -0.913 & 0.404 & -0.213 & -2.25 & 0.028 \\
\hline Neurotic & -2.15 & 0.748 & -0.312 & -2.87 & 0.006 \\
\hline Personal & 2.77 & 0.859 & 0.368 & 3.23 & 0.002 \\
\hline
\end{tabular}


Criterion variable: coming-to-terms behavior

The results presented in table 4 show the share of each variable entering coming-to-terms behavior prediction model. As it can be seen, the greatest beta coefficient is 2.77 , which is related to personal supporter. This result shows that "personal supportive factors" play a greater role in the expression of coming-to-terms behavior. In other words, there are stronger personal supportive factors that predict students' "coming-to-terms" behavior.

\section{Results}

Based on the findings of the present research, it can be concluded that there is a relationship between developed defense mechanisms. In addition, from predictor variables, personal supportive factors had a greater share in the expression of students' coming-to-terms behavior. This result is in congruence with the result obtained from researches conducted by Javaheri, Qanbari, and Zarandi (2011); Ahadi, Azizinejad, Narimani, and Berahmand (2008); and Norouzi Dayni (2002). The results of these studies showed that there is a relationship between parents' defense mechanisms and personal and social supportive factors with individuals' coming-to-terms behavior and strategies for fighting stress. It can be concluded that different defense mechanisms affect stressful emotions in various ways; some effects are positive and constructive, and some other are destructive and negative in terms of individuals' mental health. These results refer to consultants and experts' attention to the role of defense mechanisms in experiencing negative emotions and mental health. By helping patients to develop their defense mechanisms and review personal and social supportive factors, we can expect them to better come to terms with negative emotions. It is recommended that academic instructors try to encourage students to constructively interact with their parents in order to become capable of fighting stress factors. It is suggested that academic workshops are run for parents so that they can enhance the effect of their behaviors on their children. A longitudinal research was done in order to determine the role of defense mechanisms and stress fight styles in mental development process and in different educational levels.

\section{References}

Cramer, P., \& College, W. (2002). Defense Mechanism, Behavior and Affect in Young Adulthood. Journal of personality, Vol. 70, 103-126.

Dadsetan, P., Asgari, M. and Hajizadegan, M. (2009). Final report on a research in the field of validation and standardization of coping strategies in Islamic Azad University Students, Islamic Azad University, South Tehran Branch.

Dadsetan, P., Asgari, M. and Hajizadegan, M. (2009). Development of a coping strategies scale in students: two parallel form, Iranian Journal of Psychology, 217-231.

Folkman, S. (1984).” Personal control, stress and coping processes: A theoretical analysis". Journal of personality and social psychology.46, 839-852.

Ghaedi, Gh.H. and Yaghubi, H. (2008). Study of the relationship between the dimensions of 


\section{Macrothink}

International Journal of Learning and Development

ISSN 2164-4063 2016, Vol. 6, No. 1

perceived social support and dimensions of well-being in male and female students, Journal of Knowledge Brought, 81, 50-69.

Ginsburg, G. S., Riddle, M. A., \& Davies, M. (2006).” Somatic symptoms in children and adolescents with anxiety disorders". Journal of the American Academy of Child \& Adolescent Psychiatry, 45, 1179-187. 162.

Greenberg MT. Promoting resilience in children and youth; preventive intervention and their interface with neuroscience. Ann N Y Acad Sci. 2006; 1094:139-50.

Joshi, Vinay. (2007). Stress from burnout to balance, Response Books. A division of Sage Publications, New Delhi / Thousand Oaks / London.

Kashani, j. H. Orvaschel, H. (1990)." A community study of anxiety in children and parent and gender of adolescents”. Journal of adolescence. 27(6), 599-610. 164.

Lazarus, R. S., \& Folkman, S. (1984). Stress, appraisal, and coping. New York: Springer. Lind storm.

Luthar SS, Ziegler E. Resilience is not one-dimensional construct: Insights from a prospective study of inner-city adolescents. Dev Psychopathol. 1994; 5:703-17.

Sarafino, Edward, P. (2002). Health Psychology, Translated by: Abhari et al., Tehran: Roshd Press.

Werner E. High-risk children in youth adulthood: A longitudinal study from birth to 32 years. Am J Orthopsychiatry. 1989; 59:72-81. 